\title{
Surface Correspondence and Discrete Harmony Triggers
}

\author{
Rachel Walker \\ University of Southern California
}

\section{Introduction}

In this paper, I examine formal properties of surface correspondence and their empirical predictions for languages with partially overlapping harmony patterns. Surface correspondence was introduced as a basis for enforcing feature agreement and disagreement among segments in an output (Walker 2000a). Originating studies focused on consonant harmony, for which surface correspondence offered insights on properties such as the potential for action-at-a-distance and the propensity for interactions among similar segments (Walker 2000b, 2001, Hansson 2001, 2010, Rose \& Walker 2004). In the last decade, the range of phenomena to which surface correspondence has been applied has considerably enlarged, including extensions to effects that are purely local. Beyond consonant harmony, patterns that have been analyzed using surface correspondence include vowel harmony (Hansson 2006a, Sasa 2009, Walker 2009, Rhodes 2012, Bowman \& Lokshin 2014), vowel nasalization harmony (Sylak-Glassman, Farmer \& Michael 2014), dissimilation (Bennett 2013, to appear), tonal contour phenomena (Shih \& Inkelas 2014), consonant-tone interactions (Shih 2013), and restrictions on nasal-consonant sequences (Inkelas \& Shih 2014), among others. Collectively, these studies provide motivation for pursuing surface correspondence as a potential approach to (dis)agreement phenomena in general.

This paper considers the capacity of surface correspondence to manage distinct harmony patterns whose participants partially overlap. I identify a novel and problematic typological prediction of transitive surface correspondence relations with chain-adjacent evaluation of identity, dubbed the closest correspondent trigger prediction. According to this prediction, a closest correspondent in the surface correspondence chain is expected to control all harmony in a prospective target segment. I demonstrate the problematic nature of this prediction with reference to two overlapping harmonies in the dialect of Pasiego Montañes, where a target vowel agrees with distinct trigger segments for different features in a configuration that does not conform with a closest correspondent trigger. To resolve this issue, I propose a feature-restricted evaluation of identity constraints that operate over surface correspondents, where evaluation is restricted to those segments that share a given set of features. This move merges the previous division of labor in surface correspondence theory between constraints that promote interactions among similar segments and those that enforce identity between such segments.

The organization of the paper is as follows. In section 2, I show how the prediction of closest correspondent triggers follows under a given set of assumptions about the formal properties of surface correspondence. In section 3, I present data from the Pasiego Montañes dialect illustrating centralization harmony and unstressed vowel raising harmony, two patterns that partially overlap. Section 4 outlines how these patterns present problems for the closest correspondent trigger prediction. The proposal of featurerestricted evaluation of identity constraints for surface correspondents is developed in section 5, with application to a case of transparency in centralization harmony. Section 6 considers alternative strategies for overcoming the problematic predictions for partially overlapping harmonies, and section 7 discusses future directions for the theory and presents the conclusion.

\footnotetext{
* For discussion of this work at various stages, I am grateful to Eric Baković, Will Bennett, Robert Daland, Gunnar Hansson, Bruce Hayes, Kevin McMullin, Kie Zuraw and audiences at the 2014 Annual Meeting in Phonology, UCLA, and the 2015 annual meeting of the Linguistic Society of America.
}

(C) 2015 Rachel Walker

Proceedings of $A M P 2014$

Completed January 31, 2015 


\section{Closest Correspondent Triggers}

To begin, I review two existing claims about the formal nature of surface correspondence. First, Bennett (2013) proposes that surface correspondence relations are transitive. This means that if segment S1 is in a surface correspondence relation with segment $\mathrm{S} 2$, and $\mathrm{S} 2$ is in a surface correspondence relation with segment S3, then S1 and S3 are in a surface correspondence relation. Second, Hansson (2006b, 2007) proposes that IDENT-XX(F) constraints are evaluated over segments that are adjacent in the surface correspondence chain. Hence, in a corresponding sequence $\left[\ldots \mathrm{S} 1_{\mathrm{x}} \ldots \mathrm{S} 2_{\mathrm{x}} \ldots \mathrm{S} 3_{\mathrm{x}} \ldots\right]$, IDENT-XX(F) enforces identity for feature $[\mathrm{F}]$ between $\mathrm{S} 1$ and S2 and S2 and S3, but not S1 and S3. Hansson argues that local evaluation of IDENT-XX(F) constraints avoids problematic predictions that occur under global evaluation regarding majority rule effects and indeterminacy of triggers in chains with many correspondents. Together these claims predict that a segment will belong to no more than one surface correspondence chain and a harmony trigger will be chain-adjacent to its target. Here, trigger refers to the segment with which agreement is enforced by IDENT-XX(F) in a harmonizing segment.

These predictions give rise to the closest correspondent trigger prediction. In the surface correspondence chain $\left[S 1_{x} \ldots S 2_{x} \ldots S 3_{x}\right]$, where $\mathrm{S} 2$ is the only chain-adjacent correspondent of $\mathrm{S} 1$, any harmony targeting S1 will be controlled by S2, because IDENT-XX(F) is enforced only among adjacent correspondents. Thus, a pattern where harmony is observed from S2 to S1 is expected to exclude the potential for harmony in S1 for another feature from S3, where S2 intervenes between S3 and S1. This prediction is illustrated in (1a). If S1 harmonizes for feature [F] with S2, then harmony for feature $[\mathrm{G}]$ is possible with $\mathrm{S} 2$, but harmony for $[\mathrm{G}]$ is not expected to be enforced between $\mathrm{S} 1$ and a more distant correspondent S3. ${ }^{1}$

a. Closest correspondent triggers only

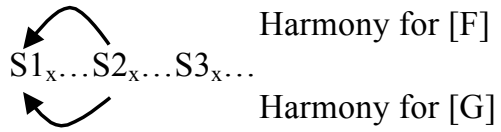

b. Discrete triggers, at different distances

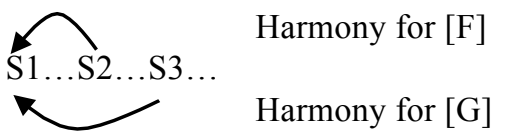

In other approaches, harmony is typically driven by constraints that regulate the distribution of individual features rather than being mediated by correspondence at the segment level (e.g. ALIGN(F),

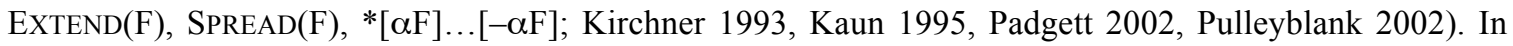
systems where transparent segments are possible, feature-specific distributional restrictions allow the possibility of a discrete trigger pattern as in (1b), where a target segment harmonizes with distinct trigger segments, one of which is further from the target than the other. The prediction of closest correspondent triggers does not appear to have been an intended theoretical implication, and to the best of my knowledge, it does not reflect a known or expected typological property of harmony systems. These issues point to it being an unwanted prediction. In the next section, the problem is examined further in relation to overlapping harmonies in Pasiego.

\section{Harmony in the Pasiego Montañes Dialect}

The Pasiego Montañes dialect (spoken in the region of Cantabria, Spain) shows a rich and complex set of vowel patterns. Overlap between two of its harmonies, centralization harmony and unstressed vowel raising harmony, serves to demonstrate the problematic nature of the closest correspondent trigger prediction. The data and description for Pasiego are based on Penny (1969a, b, 1970) with insights from interpretation and analysis by McCarthy (1984), Vago (1988) and Hualde (1989).

3.1 Centralization harmony The Pasiego dialect has a five vowel phoneme inventory: /i e a o u/. Noncontrastive centralized counterparts of vowels can be derived. Centralized vowels are transcribed using

\footnotetext{
${ }^{1}$ The exclusion of another trigger arises where two potential triggers differ in chain-adjacency with respect to the target. In $\left[S 1_{\mathrm{x}} \ldots \mathrm{S} 2_{\mathrm{x}} \ldots \mathrm{S} 3_{\mathrm{x}}\right], \mathrm{S} 2$ is chain-adjacent to both $\mathrm{S} 1$ and $\mathrm{S} 3$, and it could therefore potentially show harmony for feature [F] with $\mathrm{S} 1$ and feature [G] with $\mathrm{S} 3$.
} 
capital letters (e.g. [I], [U]). In word-final position, unstressed /u/ is regularly realized as centralized [U], but no other vowels are centralized finally. In a final unstressed syllable, the realization of $/ \mathrm{o} /$ ranges from closed [o] to open $[u]$. These noncentralized realizations are represented as $[u]$.

Centralized vowels in nonfinal syllables arise through harmony propagated from final [U], as shown in (2). Centralization harmony extends to the beginning of the phonological word, including proclitics $(2 \mathrm{e}-\mathrm{f})$. Following Hualde (1989), I assume that centralized vowels are [-ATR].
a. $\mathrm{AbI}^{\prime} \mathrm{KAnU}$
abi'Kanus
'hazelnut tree' (M.SG/PL)
b. sOl'dAU
sol'daus
'soldier' (M.SG/PL)
c. gUlUn'drInU
gulun'drina
'swallow' (M/F)
d. trAn'kIlU
tran'kilus
'calm' (M.SG/PL)
e. $k U n$ Il mA'jistrU
'with the teacher' (M.SG)
f. pAl sU'brInU
'for the nephew' (M.SG)

In Pasiego's centralization harmony, /e/ is reported to be transparent, that is, it is not perceptibly centralized and it does not block centralization from propagating to preceding vowels, as shown in (3).
a. kOmfesO'nArjU
komfeso'narjus
'confessional' (M.SG/PL)
b. kAmpe't tfAnU
kampe'tfanus
'noble' (M.SG/PL)

Hualde (1989) tentatively analyzes /e/ as undergoing centralization harmony in the phonology, with the phonetic realization of centralized [E] being no different from that of noncentralized [e]. I will assume that interpretation here, although nothing hinges on it. Under this interpretation, all vowels in Pasiego undergo centralization harmony. Nevertheless, for consistency with the transcriptions in (3), I will continue to represent /e/ in words with centralization harmony as [e].

3.2 Unstressed vowel raising harmony Unstressed vowel raising harmony causes mid vowels to raise preceding a stressed syllable that contains a high vowel $(4 \mathrm{a}-\mathrm{c})$ or a prevocalic glide $(4 \mathrm{~d}-\mathrm{e}){ }^{2}$
a. kuxi'rian
koxé'ran
'take' (3PL.COND./3PL.FUT)
b. aflu'xis
aflo'xar
'loosen' (2PL.PR.SUBJ/INF)
c. bíbia
be'ber
'drink' (1SG.IMP.IND/INF)
d. kuxx'jera
ko'xar
e. ming'war
'menus
'take' (3SG.IMP.SUBJ/INF)
'to lessen/less'

Low /a/ does not raise (5a-b), and it is transparent to unstressed raising harmony, as shown in (5c-d). Notice that like centralization harmony, unstressed raising harmony propagates to proclitics.
a. arribul'bjendu
arrebol'ber
'reddening'/'to redden'
b. amfi' $\theta$ jon
amfe'star

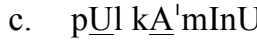
cf. po la 'kaKe
'infection'/ 'infect' (INF)
d. p $\underline{U} \underline{A} \underline{A} \tilde{r} U j U$
'by the road'/'by the street'
'by the arroyo'

At this juncture it is relevant to mention another raising harmony that occurs in Pasiego, known as metaphony. In metaphony, stressed mid vowels raise preceding a high vowel. Final [U] triggers metaphony, but not $[\mathrm{U}]$ (which is a realization of /o/), as shown in (6). ${ }^{3}$ In contexts where [U] triggers

\footnotetext{
${ }^{2}$ It appears that unstressed pretonic vowels and glides do not trigger raising harmony, as in [okali'tal] 'eucalyptus grove'. However, this aspect of the pattern is difficult to verify for certain, since lexical exceptions to unstressed raising harmony exist. See Flemming (1993) for an analysis of height harmony in Pasiego that is not stress sensitive.

${ }^{3}$ Underlying final / $-\mathrm{i} /$ also triggers metaphony, even though it is realized as [ə], e.g. /esti/ $\rightarrow$ ['istə] 'this' (M.SG), cf. ['estus] (M.PL).
} 
metaphony in /e/, centralization harmony causes raised /e/ to become perceptibly centralized [I] (6d-f). Though it is relevant for understanding patterns in the data, metaphony is not the focus of this study.
a. $\tilde{\mathrm{r}} \mathrm{A}^{\prime} \mathrm{bj} \underline{\mathrm{U}} \mathrm{sU}$
ra'bjosu
'bitter' (M.SG.COUNT/MASS)
b. 'gỮ
'gỗrdu
'thick' (M.SG.COUNT/MASS)
c. bI $\theta^{\prime} \mathrm{j} \underline{\mathrm{U}} \mathrm{sU}$
bi $\theta$ 'josus
'vicious' (M.SG/PL)
d. 'pIlU
'pelu
'hair' (M.SG.COUNT/MASS)
e. bA'bIrU
ba'berus
'bib' (M.SG/PL)
f. prI'mIrU
pri'merus
'first' (M.SG/PL)

Returning to unstressed raising harmony, this pattern interacts in a transparent fashion with Pasiego's other harmonies. First, stressed vowels that are raised due to metaphony trigger unstressed raising harmony, as in (7).
a. $\mathrm{k} \underline{\mathrm{U}} \mathbf{n}^{\prime} \underline{\operatorname{In}} \underline{\mathrm{In}}$
kon'tentus
'happy' (M.SG/PL)
b. $g \underline{U^{\prime}} 1 \underline{U} s U$
gó'losus
'sweet-toothed' (M.SG/PL)

Second, if unstressed raising harmony raises /e/ to high, it undergoes centralization harmony to [I] in words where final $[\mathrm{U}]$ is present to trigger centralization, as shown in (8).
a. $\tilde{r}^{\prime} \mathrm{dUndU}$
rédondus
'round' (M.SG/PL)
b. II'xIrU
le'xeru
'light' (M.SG.COUNT/MASS)
c. Il 'pIlU
el 'pelu
'the hair' (M.SG.COUNT/MASS)
d. $\quad$ Il $\mathrm{mA}^{\prime} \mathrm{dIrU}$
'the log' (M.SG)

Post-tonic glides do not trigger raising of stressed mid vowels, as shown in $(9 \mathrm{a}-\mathrm{b})$. Nor do post-tonic high vowels and glides trigger raising in pretonic vowels across a stressed low vowel, as seen in (9c-f).
a. i'glesja
'church' (F.SG)
b. 'medjas
'middle' (F.PL)
c. er'mAnU $^{\prime}$
'brother' (M.SG)
d. o'kalitu
'eucalyptus' (MASS)
e. $\tilde{\mathrm{r}} \underline{O}^{\prime} \mathrm{sArj} \mathrm{U}$
'backbone' (M.SG)
f. r̃e'kapjus
'bee swarm' (M.PL)

The examples in (9) diagnose that enforcement of unstressed raising harmony in (10), where nonlow pretonic vowels must be high, is due to harmony with [j] in the stressed syllable and not post-tonic [U].
a. $1 \mathrm{Um}^{\prime} \mathrm{j} \mathrm{AkU}$
'slug' (M.SG)
b. $\tilde{\mathrm{r} U m} \mathrm{~m}^{\prime} \mathrm{j} \mathrm{AxU}$
'cow slobber' (M.SG)

3.3 Summary In summary, unstressed vowel raising harmony operates from high vowels and prevocalic glides in a stressed syllable to preceding mid vowels; /a/ is transparent. Centralization harmony operates from final $[\mathrm{U}]$ to all vowels, though /e/ is interpreted as undergoing centralization harmony without perceptual effect. When /e/ raises due to unstressed raising harmony or metaphony, it becomes perceptibly centralized $[\mathrm{I}]$ in contexts for centralization harmony.

\section{Problems for the Closest Correspondent Trigger Prediction}

Recall that according to the closest correspondent trigger prediction, a harmony trigger will be adjacent to its target in the surface correspondence chain. Interactions between centralization harmony and unstressed raising harmony present a problem for this prediction. Consider the examples in (11). 

a. $1 \mathrm{Um}^{\prime} \mathrm{j} \mathrm{AkU}$
'slug' (M.SG)
b. pUl kA'mInU
'by the road'

In (11a), the first [U] harmonizes with [j] for [+high] by the dictates of unstressed raising harmony, and it harmonizes with [A] for [-ATR] via centralization harmony. In (11b), the first [U] harmonizes with [I] for [+high] and with [A] for [-ATR], the latter relation following the reasonable assumption that centralization harmony operates from the closest centralized vowel. The harmony configurations in each of these words thus plausibly involve harmony between the first vowel and two discrete triggers that follow it. Under the closest correspondent trigger prediction, harmony from the more distant trigger should not be possible because a closer trigger intervenes.

The formal workings of the problem are illustrated with the following correspondence indexing for the form in (11a): [ $1 \mathrm{U}_{\mathrm{x}} \mathrm{m}^{\prime} \mathrm{j}_{\mathrm{x}} \mathrm{A}_{\mathrm{x}} \mathrm{k} \mathrm{U}_{\mathrm{x}}$ ]. Here all vowels and glides belong to a single surface correspondence chain, obeying transitivity. If IDENT-XX(F) is evaluated locally in the chain, then harmony affecting the first vowel, should operate solely from [j], which is the first vowel's only chain-adjacent correspondent. This makes the correct prediction about unstressed raising harmony, because [j] is [+high]. However, [j] is characterized as noncentralized, so centralization of the first vowel is not predicted.

In what follows, the example in (11a) will be used a demonstration object to illustrate surface correspondence relations in a form involving discrete triggers. The noncentralized status of [j] in Pasiego remains to be instrumentally studied. Even if it were shown to be centralized, the closest correspondent trigger prediction still needs to be resolved for Pasiego for cases like (11b), where unstressed raising harmony in the first vowel is not prevented by a closer low vowel trigger for centralization harmony. In addition, as mentioned in section 2 , the exclusion of discrete triggers appears to be an unwanted implication of the theory in general.

\section{Discrete Triggers in Surface Correspondence}

In order to address the closest correspondent trigger problem, I propose an approach that introduces a feature-restricted evaluation of IDENT-XX(F) constraints. In section 6, I consider an alternative strategy that permits nontransitive surface correspondence and determine that it is problematic.

5.1 Core constraints for harmony in surface correspondence Three basic types of constraints lie at the heart of an analysis of harmony driven by surface correspondence. These are given in (12).

a. $\operatorname{IDENT}-\mathrm{XX}(\mathrm{F})$ :

Assign a violation to any pair of corresponding segments in the output that do not match in their value for $[\mathrm{F}]$. Evaluated over chain-adjacent pairs.

b. CORR-XX:

Assign a violation to any pair of segments that are not in correspondence in the output.

c. IDENT-IO(F):

Assign a violation to any pair of segments, $\alpha$ and $\beta$, where $\alpha$ is a segment in the input and $\beta$ is a correspondent of $\alpha$ in the output, and $\alpha$ and $\beta$ do not match in their value for [F].

In $(12 \mathrm{a}-\mathrm{b})$, "XX" refers to pairs of segments that belong to the output. IDENT-XX(F) constraints enforce identity for a given feature among segments that stand in correspondence in an output. The CORR-XX constraint drives correspondence among segments in an output. Traditionally, CORR constraints constitute a family, with each constraint instantiation restricted to segments that share a set of specified features (Walker 2000a, b, 2001, Hansson 2001, 2010, Rose \& Walker 2004). However, McCarthy (2010) and Shih (2013) have proposed to minimize or remove reference to features in the CORR constraint, and limit feature-specific reference in surface correspondence constraints to IDENT-XX(F) alone. I follow their lead, though I will propose a revised version of how features may be referenced in IDENT-XX(F) constraints.

Harmony for $[\mathrm{F}]$ is enforced when the constraint that drives correspondence among the harmonizing segments (CORR-XX) and the constraint that drives agreement for [F] between them (IDENT-XX(F)) both dominate IDENT-IO(F), which drives faithfulness to the segments' input value for $[\mathrm{F}]$ (McCarthy \& Prince 
1995). Thus, the ranking schema for harmony for feature [F] driven by surface correspondence is IDENTXX(F), CORR-XX >> IDENT-IO(F).

5.2 Analysis: Transparency of [j] in centralization harmony To demonstrate the analysis of discrete triggers in surface correspondence, I will concentrate on the case of transparency of [j] in centralization harmony. Recall that the problem illustrated by [IUm'jAkU] 'slug' (M.SG) is that the first [U] harmonizes with [j] for [+high] and with $[\mathrm{A}]$ for [-ATR]. [j] is transparent to centralization harmony between the first $[\mathrm{U}]$ and $[\mathrm{A}]$, though [j] itself triggers unstressed vowel raising harmony in the first $[\mathrm{U}]$. This is a configuration with discrete triggers for different harmonies in the first vowel.

To capture this configuration, I propose feature-restricted evaluation of surface correspondence identity constraints. This approach situates the labor of defining the set of segments over which harmony for $[\mathrm{F}]$ is enforced within the IDENT-XX(F) constraint. Specifically, a feature-restriction on an IDENT$\mathrm{XX}(\mathrm{F})$ constraint defines the correspondence sequence over which identity for $[\mathrm{F}]$ is evaluated. This move enables harmony for different features to be enforced over different correspondence sequences to which a segment belongs, and it thereby permits the characterization of discrete triggers for harmony in that segment.

Feature-restricted surface correspondence identity constraints are framed as IDENT-XX $\left.\left.\mathrm{X}_{\alpha \alpha \mathrm{G}(}, \beta \mathrm{H}, \ldots\right)\right](\mathrm{F})$. This constraint will enforce identity for feature $[\mathrm{F}]$ among segments in a surface correspondence relation that are specified $[\alpha \mathrm{G}(, \beta \mathrm{H}, \ldots)]$ (henceforth simplified to $[\alpha \mathrm{G}]$ ). In this approach, $[\alpha \mathrm{G}]$ is the similarity factor; it defines the segments that share some property over which agreement for [F] is enforced.

The constraint in (13) will restrict the operation of centralization harmony to vowels only. The [+vocalic] restriction will enforce evaluation of identity for [ATR] over corresponding vowels in the output, but not glides and nonvocalic segments. (On the feature [vocalic], see Padgett 2008.)

IDENT-XX[+vocalic](ATR)

Assign a violation to corresponding [+vocalic] segments in the output that do not match in value for [ATR]. Evaluated over pairs that are adjacent in the chain defined by [+vocalic].

If CORR-XX drives correspondence among all segments in the output, as in $\left[1_{x} U_{x} m_{x}{ }^{\prime} j_{x} A_{x} k_{x} U_{x}\right]$, the correspondence chain defined by [+vocalic] will be the ordered substring of vowels, that is [U, A, U]. Evaluation of identity for [ATR] operates locally within this chain over adjacent elements, namely [U, A] and $[\mathrm{A}, \mathrm{U}]$. Importantly, [j] is nevertheless in correspondence with the vowels, allowing it to interact with them for purposes of triggering unstressed raising harmony.

Evaluation of the identity constraint that enforces unstressed vowel raising harmony will be restricted to a different set of corresponding output segments, namely, those that are [-low]: IDENT-XX[-low](high). Assuming that glides are [-low], this restriction limits enforcement of height harmony to nonlow vowels and glides; low vowels and consonants (excepting high glides) are exempt from evaluation, obtaining the transparency of $[\mathrm{a}] /[\mathrm{A}]$ (and consonants) to height harmony. In $\left[1_{x} \mathrm{U}_{\mathrm{x}} \mathrm{m}_{\mathrm{x}}{ }^{\prime} \mathrm{j}_{\mathrm{x}} \mathrm{A}_{\mathrm{x}} \mathrm{k}_{\mathrm{x}} \mathrm{U}_{\mathrm{x}}\right]$, the correspondence chain defined by $[-\mathrm{low}]$ is $[\mathrm{U}, \mathrm{j}, \mathrm{U}]$. Feature-restricted evaluation of IDENT-XX constraints thus enables harmony for [ATR] and [high] to be enforced over different strings of segments in the output, with the potential for overlap. There are more complexities to the account of unstressed raising harmony, involving the origination of harmony from [+high] segments in stressed syllables and the regressive operation of harmony. Those details are not laid out here for reasons of space. Henceforth, "RAISING" will be the label for a cover constraint representing the constraint interaction responsible for enforcing unstressed raising harmony. RAISING will drive violations of IDENT-IO(high).

Following the ranking schema for harmony driven by surface correspondence, the constraint ranking for centralization harmony is IDENT-XX[+-vocalic](ATR), CORR-XX $>$ IDENT-IO(ATR). A tableau that shows the application of this constraint hierarchy to select [ $\left.1 \mathrm{Um}^{\prime} \mathrm{j} A \mathrm{AU}\right]$, with a glide that is transparent to centralization harmony, is given in (14). This tableau centers on demonstrating the workings of centralization harmony in this form. I consider only candidates in which final $/ \mathrm{u} /$ is centralized. The RAISING cover constraint is placed in the top tier in this tableau, because the dictates of unstressed raising harmony are respected. IDENT-IO(high) is placed in the second tier, because it is dominated by RAISING. I assume that all of the segments in the winning output correspond with one another, because there is no evidence that CORR-XX is dominated within this constraint set. At a minimum, all of the vowels and [j] 
must belong to the same correspondence set, since all vowels participate in centralization harmony and [j] is in a context to trigger unstressed vowel raising harmony. In order to more fully test the constraint interactions and correspondence relations in (14), I consider a hypothetical input with /o/ in the first syllable, which must become high to obey RAISING. Key features of the candidates are identified by companion comments in each cell. "CH" stands for centralization harmony and "URH" for unstressed raising harmony.

(14) Transparency of [j] in centralization harmony

\begin{tabular}{|c|c|c|c|}
\hline $\begin{array}{l}\text { /lomjak-u/ } \\
\text { (hypothetical input) }\end{array}$ & $\begin{array}{c}\text { CORR-XX } \\
\text { IDENT-XX } \\
\text { [+voc] } \\
\text { RAISING }\end{array}$ & $\begin{array}{l}\text { IDENT-IO } \\
\text { (ATR) }\end{array}$ & $\begin{array}{l}\text { IDENT-IO } \\
\text { (high) }\end{array}$ \\
\hline $\begin{array}{l}\text { a. } 1_{\mathrm{x}} \mathrm{U}_{\mathrm{x}} \mathrm{m}_{\mathrm{x}}{ }^{\prime} \mathrm{j}_{\mathrm{x}} \mathrm{A}_{\mathrm{x}} \mathrm{k}_{\mathrm{x}} \mathrm{U}_{\mathrm{x}} \\
\text { Winner: } C H \text { among vowels, } \\
\text { URH from [j] }\end{array}$ & & $* * *$ & * \\
\hline $\begin{array}{l}\text { b. } 1_{\mathrm{x}} \mathrm{u}_{\mathrm{x}} \mathrm{m}_{\mathrm{x}}{ }^{\prime} \mathrm{j}_{\mathrm{x}} \mathrm{a}_{\mathrm{x}} \mathrm{k}_{\mathrm{x}} \mathrm{U}_{\mathrm{x}} \\
\text { No } C H\end{array}$ & *!(IDENT-XX: $[\mathrm{a}, \mathrm{U}])$ & $*$ & $*$ \\
\hline $\begin{array}{l}\text { c. } 1_{\mathrm{x}} \mathrm{O}_{\mathrm{x}} \mathrm{m}_{\mathrm{x}}{ }^{\prime} \mathrm{j}_{\mathrm{x}} \mathrm{A}_{\mathrm{x}} \mathrm{k}_{\mathrm{x}} \mathrm{U}_{\mathrm{x}} \\
\text { No URH from [j] to [O] }\end{array}$ & *!(RAISING) & $* * *$ & \\
\hline $\begin{array}{l}\text { d. } \mathrm{l}_{\mathrm{x}} \mathrm{O}_{\mathrm{x}} \mathrm{m}_{\mathrm{x}}{ }^{\prime} \mathrm{j}_{\mathrm{x}} \mathrm{k}_{\mathrm{x}} \mathrm{U}_{\mathrm{x}} \\
\text { No URH from [j] to [O] }\end{array}$ & $* ! * * * * *(\mathrm{CORR}-\mathrm{XX})$ & $* * *$ & \\
\hline $\begin{array}{l}\text { e. } 1_{\mathrm{x}} \mathrm{U}_{\mathrm{x}} \mathrm{m}_{\mathrm{x}}{ }^{\prime} \mathrm{J}_{\mathrm{x}} \mathrm{A}_{\mathrm{x}} \mathrm{k}_{\mathrm{x}} \mathrm{U}_{\mathrm{x}} \\
\text { /j/ undergoes } C H\end{array}$ & & $* * * * !$ & $*$ \\
\hline $\begin{array}{r}\text { f. } 1_{\mathrm{x}} \mathrm{u}_{\mathrm{x}} \mathrm{m}_{\mathrm{x}}{ }^{\prime} \mathrm{j}_{\mathrm{x}} \mathrm{A}_{\mathrm{x}} \mathrm{k}_{\mathrm{x}} \mathrm{U}_{\mathrm{x}} \\
\text { CH is halted by [j] }\end{array}$ & *!(IDENT-XX: $[\mathrm{u}, \mathrm{A}])$ & $* *$ & * \\
\hline
\end{tabular}

Candidate (14a) is the winner, showing centralization harmony among the vowels and unstressed raising harmony operating between the glide and preceding vowel. This candidate obeys the three top-tier constraints in the tableau. All segments in the output stand in a single correspondence set. Surface identity for [ATR] is enforced among the vowels only, which collectively form the [+vocalic] surface correspondence chain. Three violations of IDENT-IO(ATR) are incurred for the derived centralized vowels. Raising harmony between the glide and preceding vowel incurs a violation of IDENT-IO(high). Candidate (14b) does not show centralization harmony. This candidate is ruled out by its violation of IDENT$\mathrm{XX}_{[+ \text {vocalic }]}(\mathrm{ATR})$, which assigns a violation to the $[\mathrm{a}, \mathrm{U}]$ pair in the [+vocalic] correspondence chain. In $(14 \mathrm{c})$, raising harmony does not operate from [j] to the preceding nonlow vowel. Since [j] and pretonic [O] do not agree for [high], this candidate violates RAISING, which enforces identity for [high] within a correspondence chain of [-low] segments (with further complexities, as noted above). Like (14c), (14d) does not show raising harmony between the glide and preceding vowel, in this case, because the glide does not belong to a surface correspondence set with the other segments. This candidate is ruled out by its violation of CORR-XX. In (14e), / j/ undergoes centralization harmony. The change in [ATR] value for the glide from its input value is not driven by any constraint dominating IDENT-IO(ATR). In particular, IDENT$\mathrm{XX}_{[+ \text {vocalic }]}(\mathrm{ATR})$ is restricted to evaluating the correspondence chain of [+vocalic] segments only, so centralization of $/ \mathrm{j} /$ does not improve harmonically over a candidate with a faithful noncentralized [j]. This candidate is thus ruled out by its extra violation of IDENT-IO(ATR). Finally, in (14f), centralization harmony is halted by [j]. This candidate is ruled out by its violation of IDENT-XX $\mathrm{X}_{\text {+vocalic] }}(\mathrm{ATR})$ for the nonharmonizing pair $[\mathrm{u}, \mathrm{A}]$ in the $[+$ vocalic] sequence.

To summarize, restricting the evaluation of IDENT-XX(ATR) to the [+vocalic] correspondence chain causes a glide to not belong to the chain over which [ATR] identity is enforced, rendering it transparent to centralization harmony, yet the glide still belongs to the [-low] correspondence set, enabling it to trigger unstressed raising harmony. Discrete triggers for partially overlapping harmonies are therefore possible with feature-restricted evaluation of surface correspondence identity constraints. 


\section{Alternative Strategies}

6.1 Nontransitive surface correspondence relations An alternative strategy to resolve the problem of the closest correspondent trigger prediction is to abandon the assumption that surface correspondence relations are transitive (Walker 2014). However, this shift in the formalism does not straightforwardly resolve the problem, and it presents problems of its own.

I consider two problems here. The first issue is that nontransitive correspondence results in unwanted ties. This problem is illustrated in (15), with the case of transparent [j] in centralization harmony. All candidates shown here obey the dictates of unstressed raising harmony.

(15) Problem 1: Unwanted ties

\begin{tabular}{|c|c|c|}
\hline /lomjak-u/ & RAISING & IDENT-XX(ATR) \\
\hline $\begin{array}{l}\text { a. } 1 \mathrm{U}_{\mathrm{x}, \mathrm{y}} \mathrm{m}^{\prime} \mathrm{j}_{\mathrm{x}} \mathrm{A}_{\mathrm{y}} \mathrm{kU}_{\mathrm{y}} \\
\text { Desired winner: } C H \text { among vowels, } \\
\text { URH from stressed glide }\end{array}$ & & *([U,j]) \\
\hline $\begin{array}{c}\rightarrow \text { b. } \operatorname{lu}_{\mathrm{x}, \mathrm{y}} \mathrm{m}^{\prime} \mathrm{j}_{\mathrm{x}} \mathrm{A}_{\mathrm{y}} \mathrm{k} \mathrm{U}_{\mathrm{y}} \\
\text { CH halted by }[j]\end{array}$ & & $*([\mathrm{u}, \mathrm{A}])$ \\
\hline $\begin{array}{r}\rightarrow \mathrm{c} . \mathrm{lu}_{\mathrm{x}} \mathrm{m}^{\prime} \mathrm{j}_{\mathrm{x}} \mathrm{A}_{\mathrm{x}} \mathrm{k} \mathrm{U}_{\mathrm{x}} \\
\text { CH halted by }[j]\end{array}$ & & $*([\mathrm{j}, \mathrm{A}])$ \\
\hline
\end{tabular}

Candidate (15a) makes use of nontransitive correspondence relations so that each sequence of harmonizing segments forms a correspondence chain, namely $[U, j]$ for unstressed raising harmony and $[U$, A, U] for centralization harmony. The first [U] belongs to both of these chains, because it participates in both harmonies. This candidate is the desired winner in (15), as it displays the appropriate harmony patterns, that is, centralization harmony operates among the vowels and raising harmony operates between the glide in the stressed syllable and the preceding nonlow vowel. It incurs a violation of IDENT-XX(ATR), for the $[U, j]$ pair in the correspondence chain indexed with ' $x$ '. The problem here is that even though a separate chain has been introduced between the first vowel and the glide for the purposes of transmitting height harmony, this correspondence set is still subject to evaluation by IDENT-XX(ATR), because this constraint demands agreement for [ATR] in every surface correspondence chain, not just the set indexed

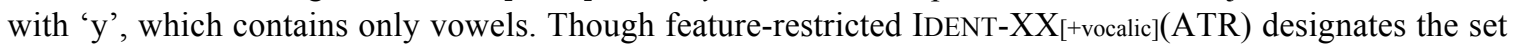
over which identity for [ATR] is evaluated, nontransitive correspondence is being considered as an alternative to that approach, so only the nonrestricted IDENT-XX(ATR) is presented.

In (15b), centralization harmony is halted by [j]. This candidate has the same surface correspondence relations as (15a), but centralization harmony does not propagate to the first vowel. Like (15a), candidate (15b) incurs a violation of IDENT-XX(ATR), but in this case it is for the [u, A] pair in the correspondence chain indexed with ' $y$ '. Candidate (15c) has the same output forms of the vowels as (15b), but it has a single surface correspondence chain, consisting of all vowels and glides. This candidate, too, incurs a single violation of IDENT-XX(ATR), in this instance for the $[\mathrm{j}, \mathrm{A}]$ pair.

The candidates in (15) thus tie by each earning a single violation of IDENT-XX(ATR), but only (15a) represents the appropriate output vowel realizations. Candidates $(15 \mathrm{a}-\mathrm{b})$ differ in whether the first vowel agrees with [j] or [A] for [ATR]. Both of these elements are closest correspondents in one of the chains to which the first vowel belongs. By contrast, in candidate (c) there is a single correspondence chain, so the first vowel must agree with its only closest correspondent, which is [j]. This candidate returns to the unwanted prediction that the glide must block centralization harmony from [A] to the first vowel, since raising harmony operates between the glide and first vowel, which is hypothesized to come about from a correspondence relation between them.

It may be possible to draw a distinction between candidates (15a) and (15b) by postulating multiple versions of IDENT-XX(ATR) so that it can be sensitive to specific values of [ATR] and also subject to directional restrictions on its evaluation; however, this is not promising as a general solution to the problem of discrete triggers, as some harmonies are enforced symmetrically over both values of a feature. 
Summing up the first problem, in systems with discrete triggers for harmony affecting the same target vowel, nontransitive surface correspondence relations allow that more than one segment could trigger harmony in the target vowel, but they do not predict which segment will trigger agreement for which harmonizing feature. ${ }^{4}$

The second problem that arises with nontransitive surface correspondence relations is the prediction of unmotivated interactions at a distance. This is illustrated in (16) with the example from (11b) where [A] is transparent to unstressed vowel raising harmony.

(16) Problem 2: Unmotivated interactions at a distance

\begin{tabular}{|l||c|c|}
\hline po $1 \mathrm{kamin}-\mathrm{u} /$ & RAISING & IDENT-XX(ATR) \\
\hline \hline$\rightarrow$ a. $\mathrm{pU}_{\mathrm{x}} 1 \mathrm{kA}_{\mathrm{y}} \mathrm{m}^{\prime} \mathrm{I}_{\mathrm{x}, \mathrm{y}} \mathrm{nU}_{\mathrm{x}}$ & $*([\mathrm{~A}, \mathrm{I}])$ & \\
Desired winner: $[$ A] transparent to $U R H$ & & \\
\hline $\begin{array}{l}\rightarrow \text { b. } \mathrm{pO}_{\mathrm{x}} 1 \mathrm{kA}_{\mathrm{x}} \mathrm{m}^{\prime} \mathrm{I}_{\mathrm{x}} \mathrm{n} \mathrm{U}_{\mathrm{x}} \\
\text { URH blocked by }[A]\end{array}$ & $*([\mathrm{~A}, \mathrm{I}])$ & \\
\hline
\end{tabular}

Candidate (16a) has the desired realizations of the vowels: raising harmony is enforced between stressed [I] and the unstressed nonlow vowel in the first syllable through the correspondence chain indexed with ' $x$ '. In this candidate, notice that centralization harmony is transmitted between the stressed vowel and the first syllable through this chain, not between the $[\mathrm{U}, \mathrm{A}]$ sequence, because the first and second vowels do not belong to the same chain. Low $[\mathrm{A}]$ is transparent to harmony transmitted through the ' $\mathrm{x}$ ' chain, but it nevertheless undergoes centralization harmony with the following $[I]$ via the chain indexed ' $y$ '. A violation of RAISING is recorded here, because identity for height is not enforced between the high stressed vowel and the preceding unstressed $[\mathrm{A}]$; recall that the restriction of enforcement to nonlow vowels is not being considered under the scenario of nontransitive correspondence relations.

In candidate (16b), unstressed vowel raising harmony is blocked by [A]. In this candidate, all of the vowels belong to a single correspondence chain. Identity for [ATR] is respected among surface correspondents. As in (16a), candidate (16b) earns a violation of raising for the [A, I] sequence in a correspondence chain. Thus, both of the candidates in (16) tie in their violation of RAISING, but only (16a) presents the attested vowel sequence for Pasiego. Even if some other constraint could be identified to favor (16a) over (16b), an issue would remain. In (16a), centralization harmony in the first vowel comes about by its relation with [I], two syllables away, and not by a relation with centralized [A] in the adjacent syllable.

The second problem for nontransitive correspondence in the analysis of Pasiego is therefore that it must posit ad hoc interactions at a distance. Specifically, in (16a), [A] is analyzed as transparent to raising harmony that affects the first $[\mathrm{U}]$, resulting from the lack of correspondence between these vowels. However, [A] must then be transparent to all harmony affecting the first [U], and centralization in the first $[\mathrm{U}]$ in this candidate arises by virtue of its correspondence with [I]. These relations do not represent the reasonable intuition that centralization harmony operates solely among adjacent syllables in Pasiego. There is no independent evidence to support centralization harmony in [U] being conditioned by a nonadjacent vowel, making this account unsatisfactory

6.2 Agreement by Projection The approach known as Agreement by Projection (Hansson 2014) is broadly similar in conceptualization to the feature-restricted IDENT-XX $[\alpha \mathrm{G}](\mathrm{F})$ constraints proposed here. In Agreement by Projection, constraints that proscribe a sequence of features that disagree in value are evaluated on a projection that is identified in the constraint by a featural restriction. A schematic example of an Agreement by Projection constraint is * $[+\mathrm{F}][-\mathrm{F}][\alpha \mathrm{G}]$. This constraint assigns a violation to a sequence $[+\mathrm{F}][-\mathrm{F}]$, where $[\mathrm{F}]$ is a given feature and the $[+\mathrm{F}][-\mathrm{F}]$ sequence is adjacent on the projection defined by $[\alpha \mathrm{G}]$. Thus, the constraint $*[+\mathrm{ATR}][-\mathrm{ATR}]\left[+{ }^{+}\right.$ocalic $]$assigns a violation to a $[+\mathrm{ATR}]$ vowel that precedes a [-ATR] vowel, where no other vowel intervenes between the vowels in question.

The projection restriction on disagreeing features in Agreement by Projection constraints has the capacity to obtain discrete triggers in a manner similar to the feature restriction in IDENT-XX[aG](F). Like

${ }^{4}$ See Lionnet (2014) for another approach to nontransitive surface correspondence relations which posits that IDENT$\mathrm{XX}$ and CORR-XX constraints can be coindexed. 
feature-restricted IDENT-XX constraints, Agreement by Projection constraints subsume both the work of similarity (i.e. which segments interact, defined in each case by $[\alpha G]$ ) and the drive for agreement (i.e. punishment for disagreement for a particular feature). However, a way in which Agreement by Projection constraints differ from IDENT-XX $[\alpha G](F)$ is that they do not employ correspondence among the interacting segments. As currently framed, both approaches to agreement are enforced over segments that are adjacent within the set identified by the $[\alpha \mathrm{G}]$ restriction. In the case of Agreement by Projection, this follows from the formal statement of the constraint. In the case of Agreement by Correspondence, enforcement of agreement among adjacent elements only (via IDENT-XX) is stipulated as a restriction governing the evaluation of the constraint. In principle, it is possible for IDENT-XX $[\alpha \mathrm{G}](\mathrm{F})$ constraints to also be evaluated over pairs that are nonadjacent in the $[\alpha G]$ correspondence set. The potential for such nonlocal interactions is therefore an area where distinct empirical predictions could be probed.

While examination of this issue lies beyond the scope of this paper, a direction to pursue is patterns where evidence exists for weaker enforcement of harmony at greater distances between the trigger and target, as in Hungarian (e.g. Hayes \& Londe 2006, Wayment 2009, Zymet 2014). A question is whether IDENT-XX $\mathrm{X}_{[\alpha \mathrm{G}]}(\mathrm{F})$ constraints with evaluation over all segments belonging to the $[\alpha \mathrm{G}]$ surface correspondence set could provide an account of such effects if refinements were developed to bias for local interactions. In particular, it would be valuable to consider whether interactions among nonadjacent elements within the correspondence chain are possible but weaker than those members that are more proximate, possibly implemented using weighted constraints in Harmonic Grammar (Legendre, Miyata \& Smolensky 1990, Smolensky \& Legendre 2006), building on the insights of the above-mentioned work on distal interactions in harmony. ${ }^{5}$ In this respect, the surface correspondence approach to agreement could offer an advantage over Agreement by Projection. In surface correspondence, the potentially interacting distal elements belong to the surface correspondence chain, supplying a relation through which they could potentially interact. In Agreement by Projection, adjacency on the projection is inherent to the constraint, at least as formulated in constraints of the type $*[+\mathrm{F}][-\mathrm{F}][\alpha \mathrm{G}]$. While this has the benefit of obtaining interactions among projection-adjacent segments without stipulation, it may be too restrictive, as gradient distance-sensitivity is not expected or available without modifying the constraint formalism.

\section{Conclusion}

The focus of this paper has been a problematic closest correspondent trigger prediction that emerges in a theory where surface correspondence relations are purely transitive and evaluation of featural identity is restricted to chain-adjacent correspondents. The proposal advanced here centers on a feature-restricted evaluation of identity constraints, formulated as IDENT-XX ${ }_{[\alpha G]}(F)$, where $[\alpha G]$ defines a subchain in the correspondence set within which IDENT-XX(F) is evaluated locally. This mechanism enables surface correspondence to capture systems with discrete harmony triggers that would otherwise be ruled out.

This proposal has implications for the architecture of a surface correspondence analysis. Featurerestricted evaluation of identity involves an enriched statement of IDENT-XX constraints. It merges the previous division of labor between constraints that promote interactions among similar segments, such as CORR-XX[aG] (also variously named CORR-CC or CORR-VV), and constraints that enforce identity between these segments. The result is a theory of surface correspondence where IDENT-XX $[\alpha G](F)$ constraints are the prime locus of pattern shaping.

A question for future research is whether CORR-XX constraints could be eliminated altogether. In the analysis developed here, CORR-XX plays a minimal role. All of the segments in the output belong to the same correspondence set, and the $[\alpha \mathrm{G}]$ restriction on IDENT-XX(F) determines which segments are required to agree for a given feature. This structure for the analysis opens the possibility that each IDENTXX constraint could simply be defined to operate over the set of output segments defined by $[\alpha G]$, without an independent violable constraint enforcing surface correspondence. Under this scenario, all segments in an output would inherently belong to a surface correspondence set, and IDENT-XX $\mathrm{X}_{[\alpha \mathrm{G}]}(\mathrm{F})$ constraints would enforce identity among segments sharing similarity as dictated by $[\alpha \mathrm{G}]$. This move would simplify the

\footnotetext{
${ }^{5}$ Note, however, that abandoning a bias for interactions among more proximate elements is problematic, as it would give rise to the issues identified by Hansson (2007), namely, unwanted majority rule effects and indeterminacy of triggers.
} 
structure of the surface correspondence approach using feature-restricted IDENT-XX constraints, and it follows thematically in line with other studies that emphasize similarity using types of IDENT constraints rather than CORR constraints (McCarthy 2010, Shih 2013).

However, the current architecture, in which CORR-XX is treated as a ranked constraint in CON, enables membership in the correspondence set to be a violable property. Eliminating this violability would lose the potential for a segment to not interact with others by not standing in a surface correspondence relation with them. As a result, patterns would be excluded where a segment is transparent to a (dis)agreement pattern because of a markedness constraint $(* \mathrm{M})$ that penalizes the outcome of that segment undergoing agreement or dissimilation. This is because the ranking $* \mathrm{M}>>$ CORR-XX would not be available. Whether this implication is empirically supported needs to be examined in further research.

As mentioned at the outset of this paper, recent research has identified benefits of applying surface correspondence in a variety of new areas, reinforcing the foundation for considering it as a potential approach for (dis)agreement phenomena in general. This paper has focused on two harmonies in Pasiego that illustrate undesirable limitations that follow from the closest correspondent trigger prediction, signaling a need to address the problem in the approach. Whether these particular harmonies are best understood in a surface correspondence account, and more generally, what range of effects surface correspondence is suitable for remains an open question. Yet the potential to handle overlapping patterns of (dis)agreement in the same language with discrete trigger control remains an important capability for the theory.

\section{References}

Bennett, William. 2013. Dissimilation, Consonant Harmony, and Surface Correspondence. Ph.D. dissertation, Rutgers University.

Bennett, William. To appear. Assimilation, dissimilation, and surface correspondence in Sundanese. Natural Language and Linguistic Theory.

Bowman, Samuel R. \& Benjamin Lokshin. 2014. Idiosyncratically transparent vowels in Kazakh. Proceedings of the 2013 Annual Meeting on Phonology.

Flemming, Edward. 1993. The role of metrical structure in segmental rules. M.A. thesis, UCLA.

Hansson, Gunnar Ó. 2001. Theoretical and Typological Issues in Consonant Harmony. Ph.D. dissertation, University of California, Berkeley.

Hansson, Gunnar Ó. 2006a. Locality and similarity in phonological agreement. Paper presented at the workshop on Current Perspectives on Phonology. Indiana University, June 23, 2006.

Hansson, Gunnar Ó. 2006b. Understanding harmony as agreement. Paper presented at the annual meeting of the Linguistic Society of America, Albuquerque, NM, January 2006.

Hansson, Gunnar Ó. 2007. Blocking effects in agreement by correspondence. Linguistic Inquiry 38, 395-409.

Hansson, Gunnar Ó. 2010. Consonant Harmony: Long-Distance Interaction in Phonology. Berkeley: University of California Press.

Hannson, Gunnar Ó. 2014. (Dis)agreement by (non)correspondence: Inspecting the foundations. Paper presented at the ABC Conference, University of California, Berkeley, May 18, 2014. [Slides archived in UC Berkeley Phonology Lab 2014 Annual Report: ABC <-> Conference Archive, 3-62.]

Hayes, Bruce \& Zsuzsa Londe. 2006. Stochastic phonological knowledge: The case of Hungarian vowel harmony. Phonology 53, 59-104.

Hualde, José I. 1989. Autosegmental and metrical spreading in the vowel-harmony systems of northwestern Spain. Linguistics 27, 773-805.

Inkelas, Sharon \& Stephanie S. Shih. 2014. Unstable surface correspondence as the source of local conspiracies. Proceedings of the $44^{\text {th }}$ North East Linguistic Society, 191-204. Amherst, MA: GLSA.

Kaun, Abigail. 1995. The Typology of Rounding Harmony: An Optimality Theoretic Approach. Ph.D. dissertation, UCLA.

Kirchner, Robert. 1993. Turkish vowel harmony and disharmony: An optimality theoretic account. Paper presented at the Rutgers Optimality Workshop 1, Rutgers University, New Brunswick, NJ, October 22, 1993.

Legendre, Geraldine, Yoshiro Miyata \& Paul Smolensky. 1990. Harmonic Grammar - A formal multi-level connectionist theory of linguistic well-formedness: An application. Proceedings of the Twelfth Annual Conference of the Cognitive Science Society, 884-891. Cambridge, MA: Lawrence Erlbaum.

Lionnet, Florian. 2014. Doubly triggered rounding harmony in Laal. Proceedings of the 2013 Annual Meeting on Phonology.

McCarthy, John J. 1984. Theoretical consequences of Montañes vowel harmony. Linguistic Inquiry 15, $291-318$. 
McCarthy, John J. 2010. Agreement by Correspondence without Corr constraints. Ms., University of Massachusetts, Amherst. (Available as ROA-1089.)

McCarthy, John J. \& Alan Prince. 1995. Faithfulness and reduplicative identity. In Jill Beckman, Laura Walsh-Dickey \& Suzanne Urbanczyk (eds.), University of Massachusetts Occasional Papers: Papers in Optimality Theory, 249384. Amherst, MA: GLSA.

Padgett, Jaye. 2002. Feature classes in phonology. Langauge 78, 81-110.

Padgett, Jaye. 2008. Glides, vowels, and features. Lingua 118, 1937-1955.

Penny, Ralph. 1969a. El habla pasiega: ensayo de dialectologia montañesa. London: Tamesis.

Penny, Ralph. 1969b. Vowel harmony in the speech of the Montes de Pas (Santander). Orbis 18, 148-166.

Penny, Ralph. 1970. Mass nouns and metaphony in the dialects of north-western Spain. Archivum Linguisticum 1, 2130 .

Pulleyblank, Douglas. 2002. Harmony drivers: No disagreement allowed. Proceedings of the $28^{\text {th }}$ Annual Meeting of the Berkeley Linguistic Society, 249-267. Berkeley, CA.

Rhodes, Russell. 2012. Vowel harmony as Agreement by Correspondence. UC Berkeley Phonology Lab Annual Report, 138-168. University of California, Berkeley.

Rose, Sharon \& Rachel Walker. 2004. A typology of consonant agreement as correspondence. Language 80, $475-531$.

Sasa, Tomomasa. 2009. Treatments of Vowel Harmony in Optimality Theory. Ph.D. dissertation, University of Iowa.

Shih, Stephanie S. 2013. Consonant-tone interaction as Agreement by Correspondence. Ms., University of California, Berkeley and Stanford University.

Shih, Stephanie S. \& Sharon Inkelas. 2014. A subsegmental correspondence approach to contour tone (dis)harmony patterns. Proceedings of the 2013 Annual Meeting on Phonology.

Smolensky, Paul \& Geraldine Legendre. 2006. The Harmonic Mind: From Neural Computation to OptimalityTheoretic Grammar. Vol. 1: Cognitive Architecture; Vol. 2: Linguistic and Philosophical Implications. Cambridge, MA: MIT Press.

Sylak-Glassman, John, Stephanie Farmer \& Lev Michael. 2014. An Agreement by Correspondence analysis of Máíhiki nasalization harmony. Paper presented at the ABC Conference, UC Berkeley, May 19, 2014. [Handout archived in UC Berkeley Phonology Lab 2014 Annual Report: ABC <-> Conference Archive, 223-287.]

Vago, Robert. 1988. Underspecification in the dual harmony system of Pasiego (Spanish). Phonology 5, 343-362.

Walker, Rachel. 2000a. Long-distance consonantal identity effects. Proceedings of the $19^{\text {th }}$ West Coast Conference on Formal Linguistics, 532-545. Somerville, MA: Cascadilla Press.

Walker, Rachel. 2000b. Yaka nasal harmony: Spreading or segmental correspondence? Proceedings of the $26^{\text {th }}$ Annual Meeting of the Berkeley Linguistic Society, 321-332. Berkeley, CA.

Walker, Rachel. 2001. Consonantal correspondence. Proceedings of the Workshop on the Lexicon in Phonetics and Phonology. Papers in Experimental and Theoretical Linguistics, Vol. 6, 73-84. Edmonton: Department of Linguistics, University of Alberta.

Walker, Rachel. 2009. Similarity-sensitive blocking and transparency in Menominee. Paper presented at the annual meeting of the Linguistic Society of America, San Francisco, CA, January 9, 2009.

Walker, Rachel. 2014. Prominence-control and multiple triggers in vowel harmony: An ABC analysis. Paper presented at the ABC Conference, UC Berkeley, May 19, 2014. [Handout archived in UC Berkeley Phonology Lab 2014 Annual Report: $A B C<->$ Conference Archive, 202-213.]

Wayment, Adam. 2009. Assimilation as Attraction: Computing Distance, Similarity, and Locality in Phonology. Ph.D. dissertation, Johns Hopkins University.

Zymet, Jesse. 2014. Distance-based decay in long-distance phonological processes: Probabilistic models for Malagasy, Latin, English and Hungarian. M.A. thesis, UCLA. 